\title{
The Monitoring And Spatial -Temporal Evolution Characteristic Analysis for Land Subsidence In Beijing
}

\author{
Qi Zhou ${ }^{1,2}$, WenJI Zhao ${ }^{2}$, Jie Yu ${ }^{2}$ \\ ${ }^{1}$ National Geomatics Center of China, Beijing, China - zhouqi@ngcc.cn \\ ${ }^{2}$ College of Geospatial Information Science and Technology, Captial Normal University, Beijing, China - zhwenji1215@163.com \\ ${ }^{2}$ College of Geospatial Information Science and Technology, Captial Normal University, Beijing, China - yuj2015@cnu.edu.cn
}

\section{Commission III, WG III/3}

KEY WORDS: Land Subsidence, D-InSAR, Small Baseline Subset (SBAS), Characteristic Analysis, Plain area

\begin{abstract}
:
At present the land subsidence has been the main geological disaster in the plain area of China, and became one of the most serious disaster that restrict the social and economic sustainable development, it also is an important content in the project of national geographic conditions monitoring. With the development of economy and society, Beijing as the capital of China has experienced significant population growth in the last few decades which led to over-exploitation of the ground water to meet the water demand of more than 20 million inhabitants, especially in the urban region with high population density. However, the rainfall and surface runoff can't satisfy the need of aquifer recharge that product the land subsidence. As China's political center and a metropolis, there are a lot of large constructions, underground traffic projects and complicated municipal pipeline network, and Beijing is also an important traffic hub for national railway and highway network, all of them would be threatened by the land subsidence disaster. In this article the author used twenty ENVISAT Synthetic Aperture Radar (SAR) images acquired in 2008 June 2010 August and ten TerraSAR images acquired in 2011 June 2012 September were processed with Small Baseline Subset SAR Interferometry (SBASInSAR) techniques, to investigate spatial and temporal patterns of land subsidence in the urban area of Beijing.
\end{abstract}

\section{INSTRUCTIONS}

Land subsidence is an environment geological disaster which is caused by natural and human factors and may induced a series of secondary damages. It is generally acknowledged that the mainly reason of the subsidence is over-exploitation of the underground resource, including underground fluid resources (ground-water, oil, natural gas, etc. ), solid mineral resources and geothermal resources, these process may lead to the decline of groundwater level, compaction and loss of porosity in the aquifer. If over-exploitation is continued for too long, porosity losses become irreversible and aquifer capacity is permanently reduced. So land subsidence is a permanent and noncompensation resources and environmental losses. In addition, uneven ground subsidence can also cause secondary geological hazards as ground fissures, which can threaten the safety of high buildings, infrastructure and underground projects and in the urban area. The situation always be irreversible and hard to recover since the land subsidence disaster formed. According to preliminary statistics, there are more than 20 provinces and 90 cities or regions occurred different degrees of land subsidence in China at present and the total settlement area reached almost $100,000 \mathrm{~km}^{2}$. There are several typical areas of land subsidence were formed such as the North China Plain, the Yangzi revier Delta Region, Suzhou-Wuxi-Changzhou region and the FenWei Basin, some areas even have induced serious ground fissure disaster. Land subsidence has become one of the main geological disasters in urban and plain areas with large scope. The subsidence disasters formed slow and the sedimentation process is hard to avoid which also lead to a series of other environmental disaster as a chain. It would take a serious degree impact to the urban construction, municipal transportation, mining enterprises and the basic security of people, which has become a major strategic issue restricting the sustatinable development of the social and enconomics.

In this article the author used Small Baseline Subset SAR Interferometry (SBAS-InSAR) techniques, to investigate spatial and temporal patterns of land subsidence in the urban area of Beijing which revealed high precision land deformation inversion, analysed and realized the influence scope and quantities of the land subsidence on urban development and construction. There would be great theoretical and realistic significance to the prevention, control, slow down the occurrence of subsidence and rational urban planning, safeguard the people to live and work in peace and the sustainable development of the economic.

\section{SBAS-INSAR EXPERIMENTAL PROCESS}

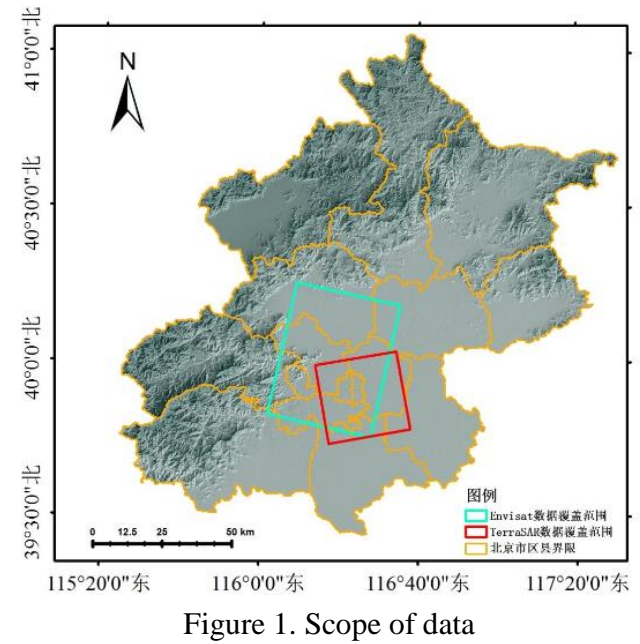


In this article the author used twenty ENVISAT Synthetic Aperture Radar (SAR) images acquired in 2008 June 2010 October and ten TerraSAR images acquired in 2011 June 2012 September which were processed with Small Baseline Subset SAR Interferometry (SBAS-InSAR) techniques to monitor the cumulative settlement of land subsidence in the study area.

\subsection{Processing of Envisat ASAR data (Medium resolution)}

2.1.1 Data acquisition Select the study area about $40 \mathrm{~km} * 50 \mathrm{~km}$ in the urban of Beijing (the blue range in Figure1). Using twenty $30 \mathrm{~m}$ resolution Envisat ASAR images acquired in 2008 June $\sim 2010$ October at a distance of 700 days for interference processing (Table 1). The external reference DEM data selects the $90 \mathrm{~m}$ resolution SRTM data which was obtained by the NASA. Setting the time-baseline threshold as 200 days and the spatial perpendicular baseline threshold is $200 \mathrm{~m}$. Then a total of 67 interferograms pairs of the 16 sub baseline sets were generated (Figure 2).

\begin{tabular}{cccc}
\hline & $\begin{array}{c}\text { Acquisition } \\
\text { Date }\end{array}$ & $\begin{array}{c}\text { Perpendicular } \\
\text { Baseline }(\mathrm{m})\end{array}$ & $\begin{array}{c}\text { Time } \\
\text { Baseline(d) }\end{array}$ \\
\hline 1 & 20080630 & -617.156 & 315 \\
2 & 20080804 & -551.84 & 280 \\
3 & 20080908 & -314.22 & 245 \\
4 & 20081013 & -754.38 & 210 \\
5 & 20081222 & -937.76 & 175 \\
6 & 20090126 & -452.37 & 140 \\
7 & 20090406 & -93.95 & -175 \\
8 & 20090511 & -717.88 & -140 \\
9 & 20090824 & -554.98 & -35 \\
10 & 20090928 & 0 & 0 \\
11 & 20091102 & -758.79 & 35 \\
12 & 20100111 & -806.63 & 105 \\
13 & 20100215 & -133.45 & 140 \\
14 & 20100322 & -500.86 & 175 \\
15 & 20100426 & -338.21 & 210 \\
16 & 20100531 & -650.63 & 245 \\
17 & 20100705 & -472.89 & 280 \\
18 & 20100809 & 44131 & 315 \\
19 & 20100913 & 44632 & 350 \\
20 & 20101018 & 45133 & 385 \\
\hline
\end{tabular}

Table 1. Envisat ASAR data list

\subsubsection{Data processing}

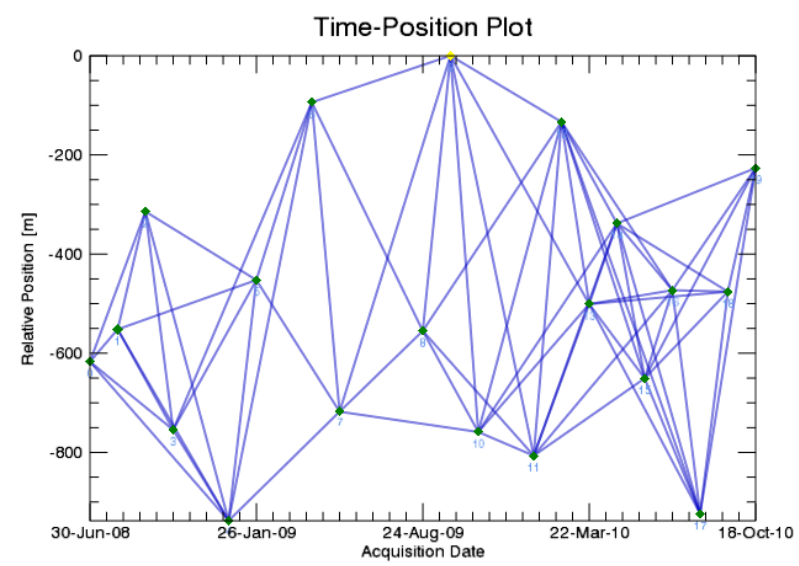

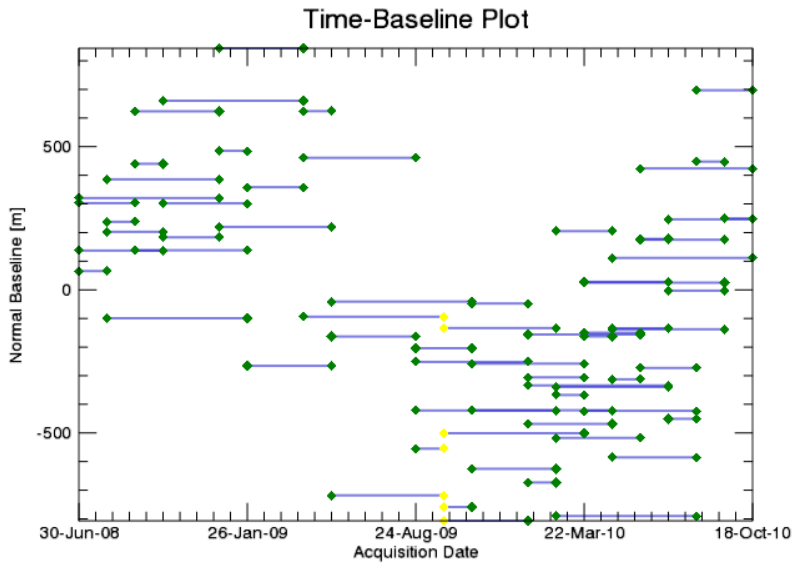

Figure 2. Connection map of the 67 interferograms

In connection diagram generating process, to all the SAR images within the range set baseline distance threshold of space and time, like the combination, set up corresponding relation, it is concluded that the connect to the Internet, according to the result of grouping for differential interference processing, can get 67 scene interference figure. SBAS method get time deformation sequence by a pixel count, in order to avoid error, low coherent point in the phase diagram in the differential interference of high coherent point target selection, and then point by point calculation. Using the average coherent value map of all SAR images, the pixels with an average coherence value greater than 0.25 are selected as high coherence points. Figure 2 shows the average coherence value map of the study area obtained by processing all images, and the base map is the intensity map of the research area. In the figure 3 , we can find the coherence of the main urban area is relatively high, but in the western mountainous area, the large suburban area in the northern Changping District and Shunyi District has low coherence.

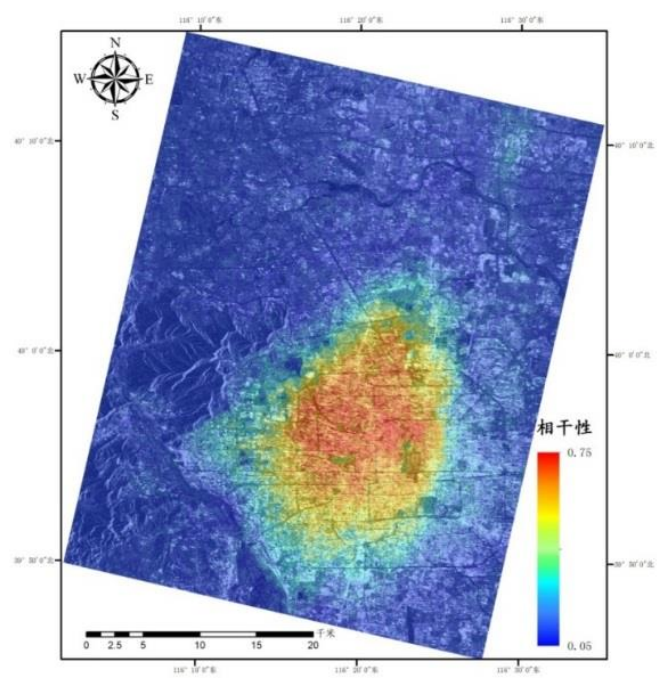

Figure 3. The mean coherence

Making Differential interference processing and filtering processing to the interferograms pairs. Then unwrapping the interferometric phase by the method of Minimum Cost Flow which based on the Delaunay triangulation network and generated 67 phase unwrapping pictures (Figure 4). 


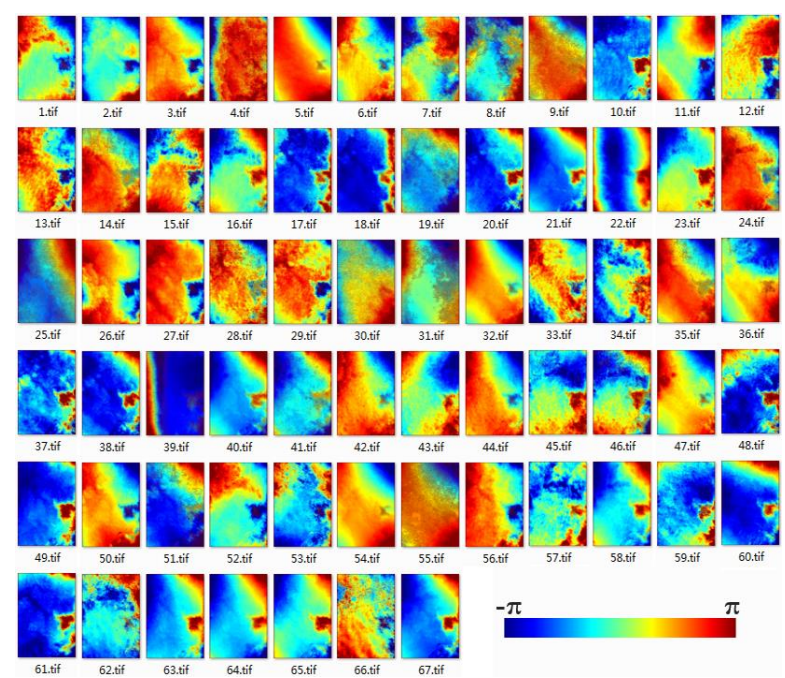

Figure 4. Unwrapping phase pictures

Estimation and removal of atmospheric delay phase and noise. For the effect of atmospheric delay, it is generally believed that it is irrelevant in time, but it has a strong correlation in space [6], which is approximated by a complex three-dimensional surface. From the perspective of signal analysis, the atmospheric delay phase is characterized by high frequency characteristics in time series and low frequency characteristics. The noise phase is high frequency signal in time and spatial distribution. Therefore, the phase is filtered through the distribution of high-pass filtering and low-pass filtering to realize the evaluation of atmospheric delay phase and noise phase (Figure 5), which can reduce the impact on monitoring result and finally generated the nonlinear deformation differential interfere phase.

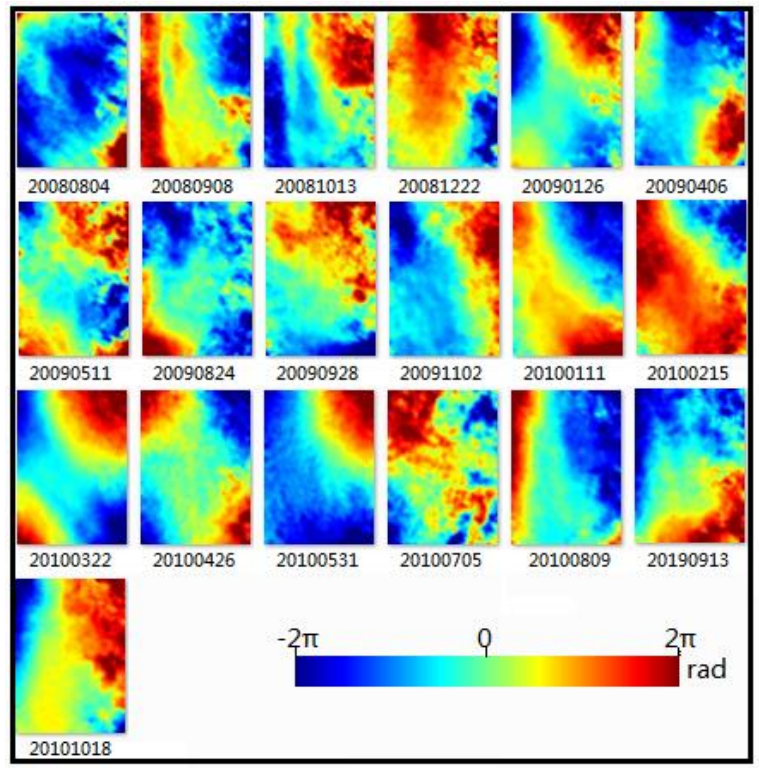

Figure 5. Time series atmospheric delay phase

Using singular value decomposition (SVD) method can get high coherent point time series sedimentation rate (as shown in Figure 6), and generated the cumulative settlement of the entire range of time series in the study area (as shown in Figure 7), we can find time to study the development of the settlement within the scope of the study area and extract the evolution characteristics.

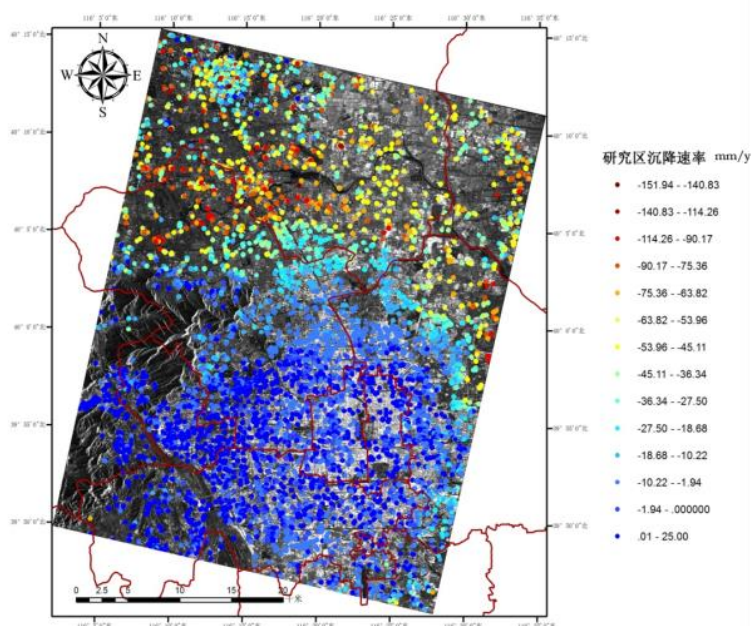

Figure 6. High coherent point time series sedimentation rate

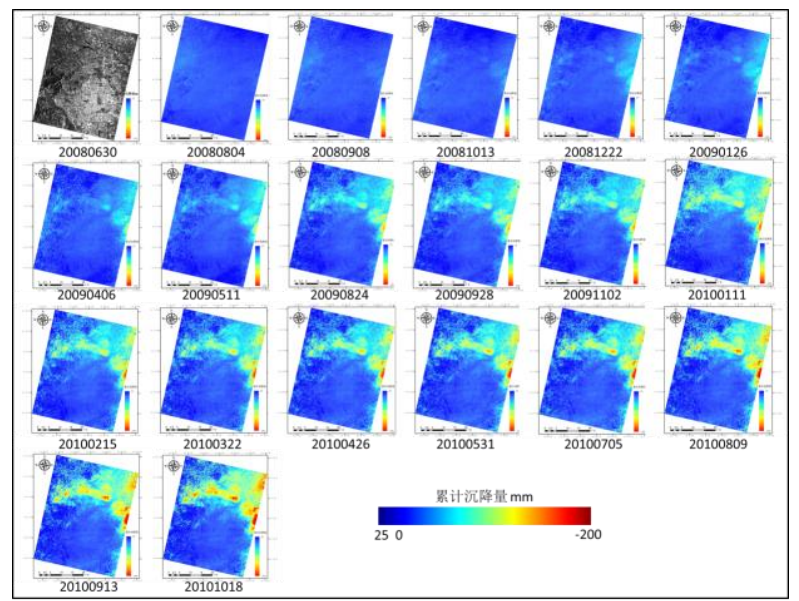

Figure 7. Time series cumulative settlement

\subsection{Processing of TerraSAR data (High resolution)}

2.2.1 Data acquisition Select the study area about $30 \mathrm{~km} * 30 \mathrm{~km}$ in the urban of Beijing (the red range in Figure1). Using ten $3 \mathrm{~m}$ resolution Envisat ASAR images acquired in 2011 June 2012 September for interference processing (Table 2). The external reference DEM data selects the $90 \mathrm{~m}$ resolution SRTM data which was obtained by the NASA. Setting the timebaseline threshold as 350 days and the spatial perpendicular baseline threshold is $300 \mathrm{~m}$. Then a total of 45 interferograms pairs of the 9 sub baseline sets were generated (Figure 8).

\begin{tabular}{cccc}
\hline & $\begin{array}{c}\text { Acquisition } \\
\text { Date }\end{array}$ & $\begin{array}{c}\text { Perpendicular } \\
\text { Baseline }(\mathrm{m})\end{array}$ & $\begin{array}{c}\text { Time } \\
\text { Baseline }(\mathrm{d})\end{array}$ \\
\hline 1 & 20110627 & -26.96 & -66 \\
2 & 20110901 & 0 & 0 \\
3 & 20110923 & 17.08 & 22 \\
4 & 201111062 & -87.21 & 66 \\
5 & 20111220 & 78.72 & 110 \\
6 & 20120202 & -198.17 & 154 \\
7 & 20120224 & 16.38 & 176 \\
8 & 20120408 & 88.47 & 220 \\
9 & 20120705 & 27.43 & 308 \\
10 & 20120909 & -389.98 & 374 \\
\hline
\end{tabular}

Table 2. TerraSAR data list 
2.2.2 Data processing The processing method is similar to the Medium resolution images processing, the processing result as below:
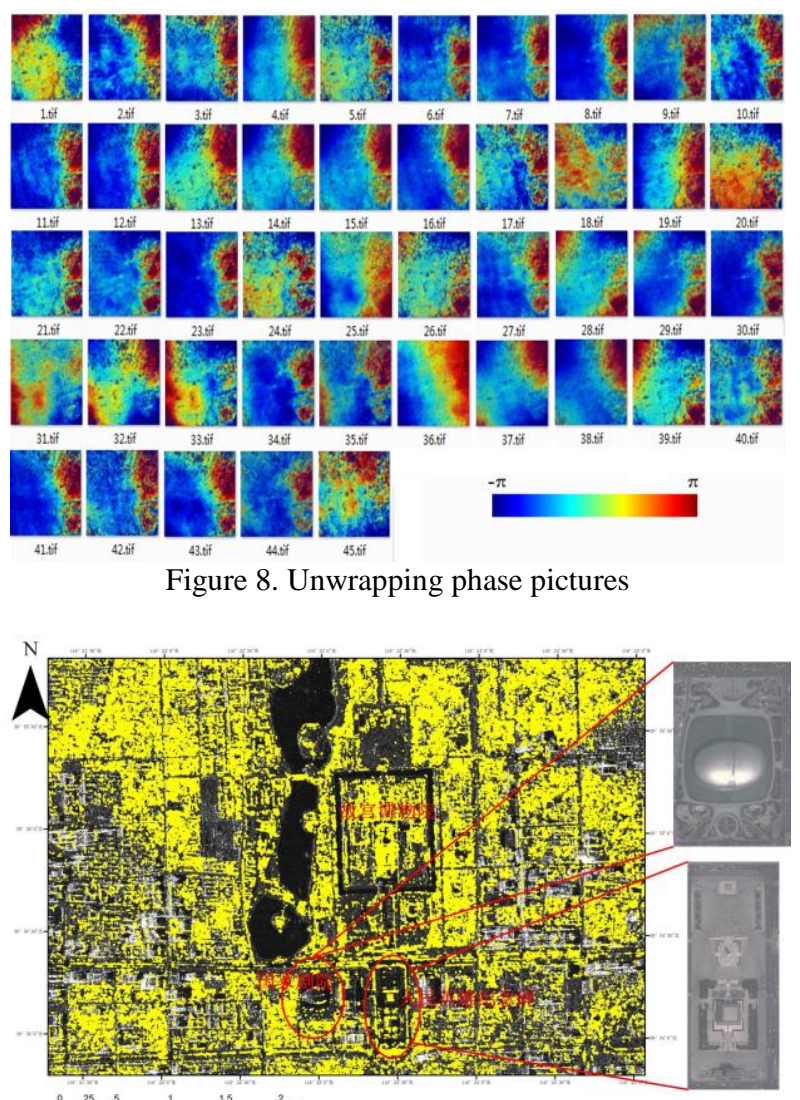

Figure 9. Coherence target point of central urban area

Select the central urban area of Beijing to show the high coherence target poin(Figure 9). Because of the high building stability in Beijing central area, the scattering characteristics of these targets have remained almost constant over time, even if the threshold is set to 0.5 , a large number of high coherence points can be obtained.

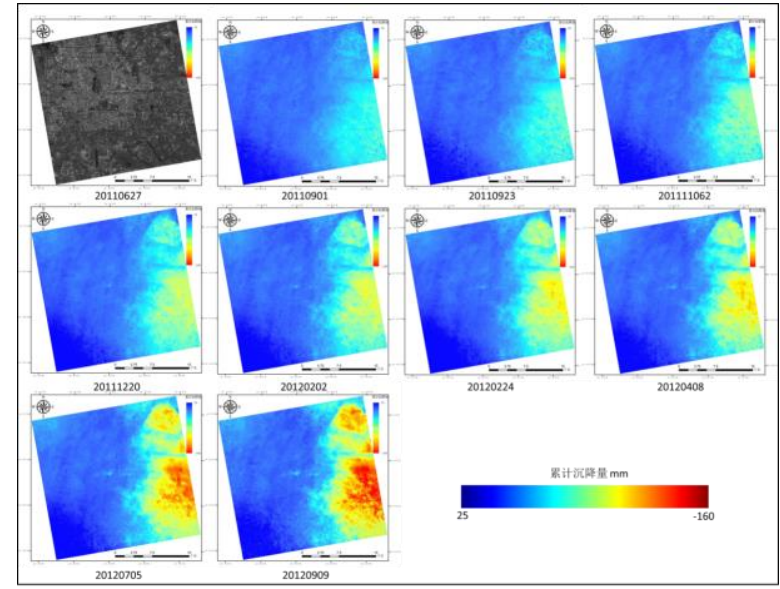

Figure 10. TerraSAR time series cumulative settlement

\subsection{The land subsidence monitoring result}

Taking the two cumulative settlement graphs which were generated by different image resolution and different time series data to superimposed under the same geographical coordinates.
At the boundary intersection of the two kind of monitoring result images, though not in the same period of settlement, however, the trend of settlement region and the geographical position are very close which proved that the monitoring result by different data is stable and reliable.

If the image is enlarged, the effect of different data source resolution on the deformation monitoring results can be found.

The spatial resolution of Terrasar-x data per pixel is more abundant and practical in some surface micro-deformation monitoring than Envisat ASAR data $30 \mathrm{~m}$ resolution. Such as in the ground fissures and large ground building deformation monitoring, deformation details is very high, deformation range and shape variables are limited, $30 \mathrm{~m}$ pixel resolution of the data is difficult to competent for this kind of monitoring requirements.

Using leveling land subsidence monitoring results isoline map of $2008 \sim 2008$ were overlay and compared the black contour of the (Figure 10), and found the cumulative settlement of InSAR monitoring results and measured by GPS network settlement center maintains highly consistent, the subsidence area also maintains consistent with those obtained development scope, through the conventional measurement results further verify the reliability of this method.

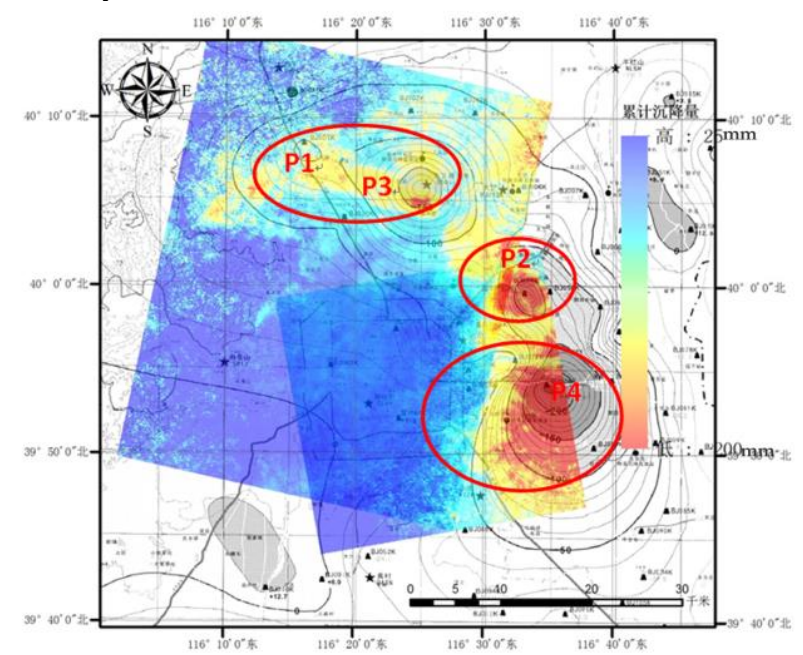

Figure 10. Insar monitoring result and contour of settlement

\section{ANALYSIS OF LAND SUBSIDENCE CHARACTERISTICS}

The spatial-temporal evolution characteristics of land subsidence and influence factors were analyzed according to the InSAR monitoring result about the velocity and distribution of the subsidence in Beijing. The image of time series settlement value illustrate that the scope and scale of the subsidence is still increasing since the groundwater as the main source of water supply which is still over-exploitation in the urban area, some subsidence center is gradually connecting to one piece, some subsidence center is gradually connecting into one piece and developing to a multicenter and widespread subsidence funnel. Furthermore, the research made analysis of the spatial-temporal evolution characteristics from the following aspect.

The SBAS-InSAR method can obtain nonlinear settlement monitoring result which shows that between December and May of the year, the time series curve graph of subsidence velocity obviously slow down, while the velocity of subsidence in summer from May to September is significantly increased, so 
the land subsidence time distribution shows seasonal characteristic obviously.

High subsidence rates are also measured on the hanging wall of major normal faults, where the thickest sequences of compressible Quaternary sediments crop out. Strong contrasts in subsidence rates are identified across major faults, suggesting that these faults act as barriers to horizontal movement of groundwater. In addition, the distribution of compressible layer thickness in the quaternary cohesive soil is consistent with that of the land subsidence center.And the subsidence areas in Beijing plain area blunt pluvial fan edge where the sedimentary centers sediment particles is small, so the compressible layer is thicker that provides conditions for subsidence.

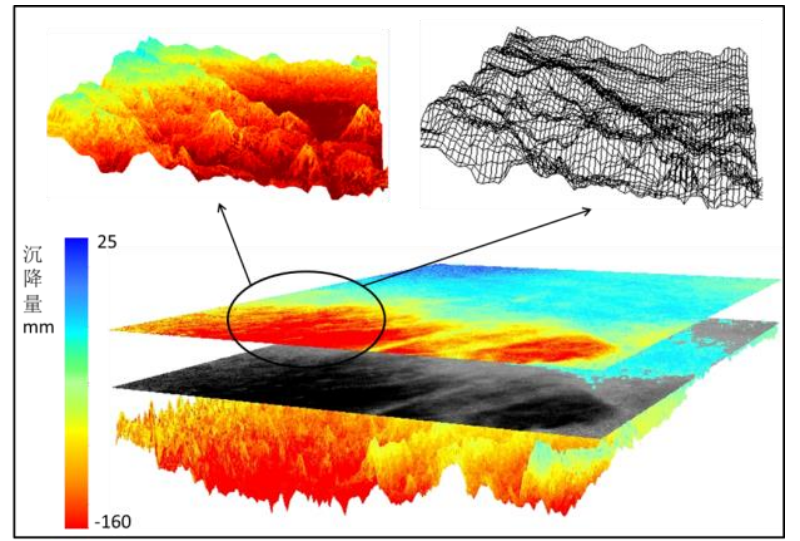

Figure 11.3D map of land subsidence funnel

The changes of groundwater level would influence the land subsidence development and distribution. In the concrete settlement, the viscous soil layer is the most severe, and the water saturation of the viscous soil is the highest, and the water plays a larger role in the viscous soil than the water in the coarse particles, so the settlement is more obvious. The land subsidence center is roughly in line with the lower part of the water head contour of the fourth aquifer group. In order to protect the water supply demand in Beijing, the exploitation of groundwater increases year by year and causing the groundwater level to drop rapidly, over-exploitation of groundwater can damage the balance of the ground, but the subsidence velocity can be slows down as long as the groundwater exploitation can be controlled reasonably and scientifically.

\section{CONCLUSION}

InSAR technology as a kind of surface deformation monitoring of the rapid development of the technology, with its high monitoring precision, wide coverage, the application of low cost, short repeated cycle of advantages, is widely used in the ground deformation monitoring. Short baseline interferometry set method SBAS - InSAR technique, can be obtained in the case of a limited amount of data inversion precision ground subsidence information, solved the practice of conventional differential interferometry D-InSAR technology vulnerable time space problems such as loss of coherence, atmospheric delay effect and the influence of permanent scatterer PS-InSAR technology due to problems affected the accuracy of monitoring data volume limitation.

The typical areas of land subsidence in monitoring scope of cumulative settlement, the subsidence, sedimentation rate, on the basis of further deformation of central space-time evolution characteristics, the analysis of the law of development, combined with relevant hydrogeological data of subsidence mechanism and the research trend, for urban planning, land and resources development and provides some references for the construction of large-scale project, also for the government to hold the space for regional land subsidence distribution and change rule, provide basic information for scientific and effective settlement of prevention and control measures.

\section{REFERENCES}

Xixin Z.,Qiang W., Yansheng H.., Yufei Y.,2002. Some Frontier Problems on Land Subsidence Research In Acta Geoscientica Sinica ,23(3),pp.279-282.

Yuepign Y.,Zuochen Z.,Kaijun Z.,2005.Land subsidence and countermeasures for its prevention in China THE CHINESE JOURNAL OF GEOLOGICAL HAZARD AND CONTROL ,16(2)pp.1-8.

Agen Z.,Zixin W.,2005. Land subsidence in China.Shanghai,China,pp.20-22.

Cong L.,Xiaojun Y.,Jinqi Z.,2004. Suxi Chang cracks.Beijing,China,pp.15-18.

Zixin W.,Hanmei W.,Jianzhong W.,2009. Land subsidence in Shanghai and its impact on urban security. Shanghai Geology. (01),pp.34-39.

COLESANTI C., FERRETTI A., PRATI C.,2003. Monitoring Landslides and Tectonic Motions with the Permanent Scatters Technique.Engineering Geology, 68,pp.3-14.

Yongliang X.,Dingfa H.,Xiaoli D.,2005. Research on Tropospheric Delay Correction Model Based on Multiple GPS Reference Stations. Geotechnical Investigation \& Surveying. (5),pp.57,64.

XiaoJun L., Guoxiang L., Dingfa H.,2005. Modeling with Permanent-Scatterer Network and Analysis of Ground Deformation and Atmospheric Influence. Journal of Remote Sensing. 12(2),pp.270-276.

ALBA Y., JORDI C., DANI M.,2014. Analysis of the evolution of ground movements in a low densely urban area by means of DInSAR technique. Engineering Geology.170,pp.52.

ANDREW H., DAVID B., KARSTEN S.,2012. Recent advances in SAR interferometry time series analysis for measuring crustal deformation. Tectonophysics.1,p.p514-517.

Yan Y.,Sanman J., Haigang W.,2010. Ground settlement status and development trend in Beijing Plain. Shanghai Land \& Resources. 31(4),pp.23-28.

DEVIN L., THOMAS J., B.2011. Review: Regional land subsidence accompanying groundwater extraction, Hydrogeology Journal. 19(8),pp.1459-1486. 